\title{
Severe eosinophilic asthma and aspirin-exacerbated respiratory disease associated to eosinophilic gastroenteritis treated with mepolizumab: a case report
}

\author{
C. Caruso ${ }^{1 *+}$, S. Colantuono ${ }^{1,2+}$, D. Pugliese ${ }^{3}$, C. Di Mario ${ }^{4}$, B. Tolusso ${ }^{5}$, E. Gremese $^{4,5}$, G. Papparella ${ }^{6}$, F. Castrì ${ }^{7}$, \\ A. Gasbarrini ${ }^{8}$, A. Romano ${ }^{9}$ and A. Armuzzi ${ }^{3}$
}

\begin{abstract}
Background: Mepolizumab (MEP) is the first anti Interleukin (IL)-5 add-on therapy approved for the treatment of severe refractory eosinophilic asthma.

Case presentation: We describe here the case of a 49 years-old woman with Aspirin-exacerbated respiratory disease (AERD), chronic rhinosinusitis, nasal polyposis and eosinophilic gastroenteritis successfully treated with MEP. Several laboratory and clinical items improved during therapy; moreover MEP showed to be useful as steroid sparing agent.

Conclusions: This case supports that the use of mepolizumab can be effective also in other eosinophilic conditions different from asthma and this opens to new therapeutic perspectives.
\end{abstract}

Keywords: AERD, Eosinophilic, Asthma, Gastroenteritis

\section{Background}

Aspirin-exacerbated respiratory disease (AERD) is characterized by chronic eosinophilic nasal polyps, asthma, and airway reactions upon cyclooxygenase (COX) 1 inhibition and affects $1.9 \%$ of the European population [1]. Eosinophilic gastroenteritis (EGE) is a rare primary eosinophilic gastrointestinal disorder (EGID), of unknown etiology, characterized by the presence of an intense eosinophilic infiltrate on histopathological examination of the gastric and intestinal mucosa.

The overall prevalence of eosinophilic enteritis is estimated at $5.1 / 100,000$ persons, with peaks of incidence between the third and fifth decade of life

\footnotetext{
*Correspondence: Cristiano.caruso@policlinicogemelli.it

${ }^{\dagger} \mathrm{C}$. Caruso and S. Colantuono equally contributed to paper

${ }^{1}$ Allergy Unit, Fondazione Policlinico Universitario A. Gemelli, IRCCS, Rome, Italy

Full list of author information is available at the end of the article
}

[2]. Hypersensitivity response seems to play a key role in pathogenesis of EGE and several patients show association with other conditions such as seasonal allergies, food allergy, asthma, and eczema.

Mepolizumab (MEP) is the first anti Interleukin (IL)-5 add-on therapy approved for the treatment of severe refractory eosinophilic asthma [3]. Eosinophil differentiation, survival, and activation are preferentially regulated by IL-5, a cytokine that binds to the IL-5 receptor (IL-5R), which is located on the surface of eosinophils or basophils and plays a critical role in the pathogenesis and severity of asthma [4]. Recently, one case report of a successfully treatment of both severe asthma and EGE with mepolizumab plus omalizumab (anti-immunoglobulin E monoclonal antibody) has been reported [5].

We describe here the case of a woman suffering from severe eosinophilic asthma and AERD associated to EGE successfully treated with MEP.

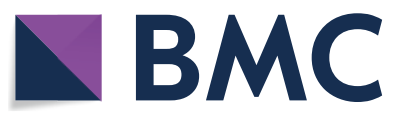

(c) The Author(s) 2020. This article is licensed under a Creative Commons Attribution 4.0 International License, which permits use, sharing, adaptation, distribution and reproduction in any medium or format, as long as you give appropriate credit to the original author(s) and the source, provide a link to the Creative Commons licence, and indicate if changes were made. The images or other third party material in this article are included in the article's Creative Commons licence, unless indicated otherwise in a credit line to the material. If material is not included in the article's Creative Commons licence and your intended use is not permitted by statutory regulation or exceeds the permitted use, you will need to obtain permission directly from the copyright holder. To view a copy of this licence, visit http://creativeco mmons.org/licenses/by/4.0/. The Creative Commons Public Domain Dedication waiver (http://creativecommons.org/publicdomain/ zero/1.0/) applies to the data made available in this article, unless otherwise stated in a credit line to the data. 


\section{Case presentation}

A 49 years-old woman with ten-year recurrent nonbloody watery diarrhea and abdominal pain came to our observation in 2015. No family history of gastrointestinal disorders was detected. A full ileocolonscopy performed 5 years before (no biopsies collected) was normal, leading to a diagnosis of an irritable bowel syndrome, so managed with symptomatic drugs without significant clinical benefit. She had also an history of repeated endoscopic sinus surgery (ESS) because of polyps' recurrence, aspirin-exacerbated respiratory disease and severe eosinophilic asthma with frequent exacerbations, requiring short courses of oral corticosteroids. Over the years, it appeared that oral steroids induced also a complete relief of gastrointestinal symptoms, with a relapse at withdrawal. Therefore, the patient had repeated steroids exposure, developing dependence and several side-effects.

At admission to our department, she complained watery diarrhea (5-6 bowel movements/day) preceded by abdominal pain. Her vital signs were: SpO2 95\% (room air), Temperature $35.8{ }^{\circ} \mathrm{C}$, Heart Rate $100 \mathrm{bpm}$, Respiratory Rate 18/m, Blood Pressure 108/60 mmHg.

Physical examination was significant only for mild tenderness in the mesogastric area with intact bowel sounds. No organomegaly was found. Visual analog scale (VAS) score for abdominal pain was moderate/ severe (60). Besides elevated peripheral blood eosinophil $\left(0.38 \times 10^{9} / \mathrm{L}\right)$ laboratory tests were unremarkable. Stool examinations were negative for parasitic, bacteria and clostridium difficile infections. Pulmonary functional tests revealed a Forced Expiratory Volume in the first second (FEV1) of 63\% (of predicted value), Asthma Control Test (ACT) score was 13, Sino-Nasal Outcome Test (SNOT-22) was 93, Lund-Mackay (LM) score was 20. Baseline mean OCS dose was $15 \mathrm{mg}$ of prednisone per day. Four OCS requiring asthmatic exacerbations occurred during the previous year.

An ileocolonscopy revealed a normal aspect of the mucosa of each explored segment, except for a small polyp $(2 \mathrm{~mm})$ in the rectum, that was removed. Biopsies collected from apparently normal mucosa showed instead an important linfoplasmacellular and granulocytic infiltrate in the lamina propria with a predominance of eosinophils (Fig. 1a, b).

Moreover, no significant findings emerged from gastroscopy, but biopsy specimens, collected in antrum, showed as well as the linfomonocytic and eosinophil granulocytic infiltrate disrupting the glandular structures (Fig. 1c).

According to the immunopathogenetic mechanisms of the diseases and in order to spare oral steroids, in 2017, we started treatment with subcutaneous MEP at the standard dose of $100 \mathrm{mg}$ every 4 weeks, using the severe eosinophilic asthma schedule.

As expected, blood eosinophil count was reduced after the first administration, and became lower and lower during the next 48 weeks $\left(30\right.$ cells $/ \mathrm{mm}^{3}$ ). After 3 months, patient experienced a significant improvement of sinusitic, respiratory as well as gastrointestinal symptoms. FEV1 and SNOT-22 were evaluated at 6 and 12 month, showing a global improvement (75\% and 95\%; 51 and 21 respectively). $\mathrm{ACT}$ raised to 23. LM score reduced to 8 at month 12. VAS score for abdominal pain reduced to 20 after 3 months so gradually all oral corticosteroids were successfully reduced by patient. After 6 months, patient was in steroid-free clinical remission with a stool frequency of 1-2 movements/day of normal feces (type 3 according to the Bristol stool chart) and a complete resolution of abdominal pain. BMI (Body Mass Index) reduced from 28 to 23 and none asthma exacerbation occurred during the first year of treatment and until the last follow-up evaluation (24 months) [6].

Endoscopies were repeated in order to obtain new biopsy specimens, showing a remission of the disease in term of eosinophilic inflammation, glands where normal and neither reactive hyperchromatic changes, nor mucin depletion can be appreciated (Fig. 1d-f).

Basophils activation was evaluated after 12 months of MEP, using the surface molecules CD203c, CD63 and CD125, showing a reduction of activation percentages. Results are shown in Fig. 2a, b [7]. Serum IL-5 levels (R\&D Systems; sensitivity: $0.29 \mathrm{pg} / \mathrm{ml}$ ) were measured at baseline and after 3, 6 and 12 months of treatment and are shown in Fig. 2. Serum IL-5 was non-quantifiable at baseline and showed an increase with peak on 6 months as expected and previously demonstrated by Pouliquen et al. in 2015 (Fig. 2c) [8].

\section{Discussion}

The case of this woman affected by AERD, chronic rhinosinusitis, nasal polyposis and EGE successfully treated with MEP supports recent literature data that show how new biological agents may be useful in 


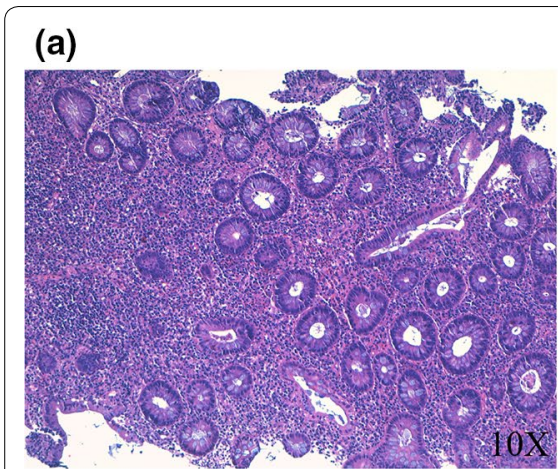

(d)

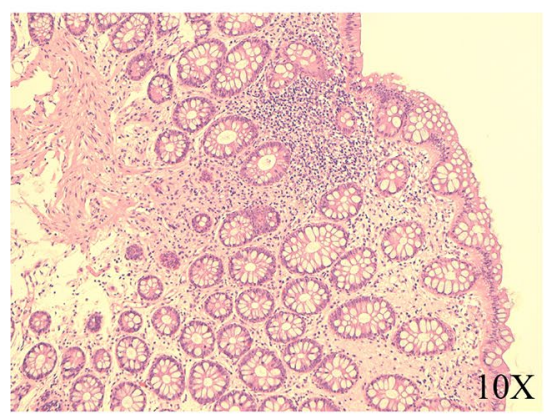

(b)

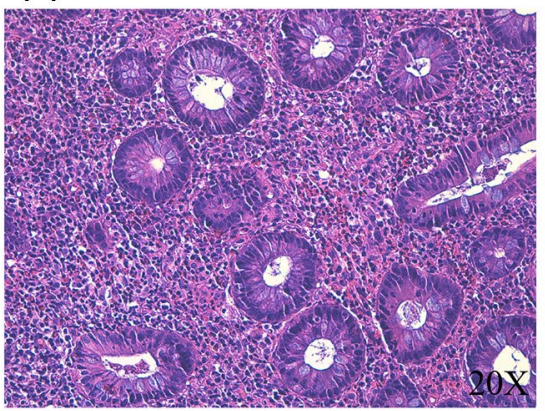

(e)

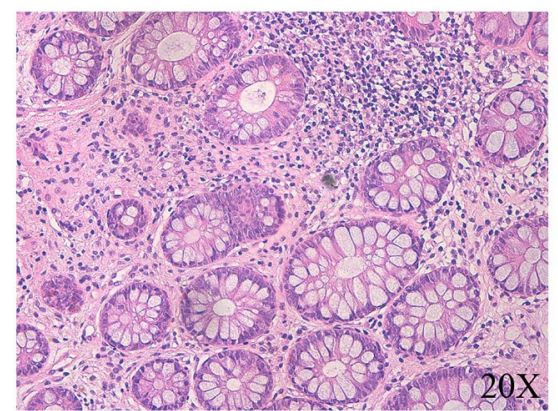

(c)

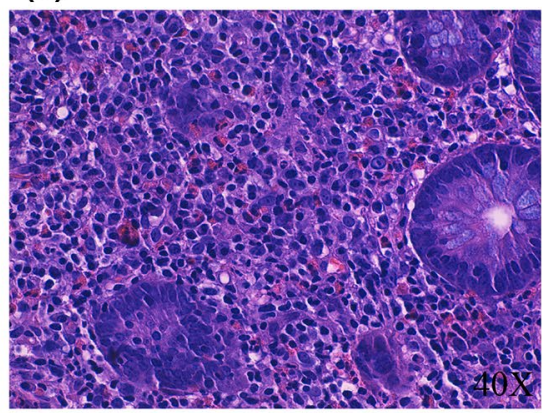

(f)

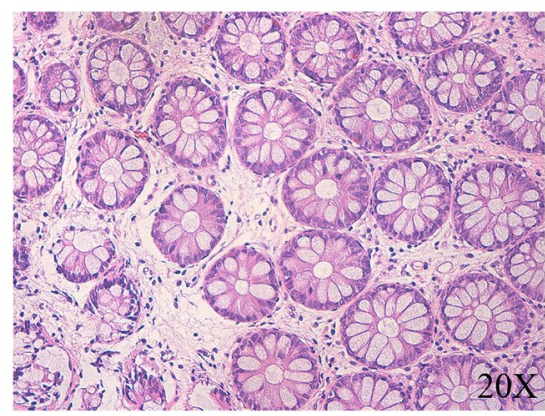

Fig. 1 a (Hematoxylin and Eosin, $\times 10)$ : in this picture an important linfoplasmacellular ad granulocytic infiltrate is appreciable in the lamina propria with a predominance of eosinophilis, with an infiltrating pattern sometimes disrupting glandular integrity. $\mathbf{b}$ (Hematoxylin and Eosin, $\times 20$ ): a particular of the previous where eosinophils granulocytes surround and infiltrate the glands. As a consequence, glandular structures are depleted of their goblet cells and show reactive hyperchromatic nuclei. c (Hematoxylin and Eosin, $\times 40$ ): this is an atrophic field where the linfomonocytic and eosinophil granulocitic infiltrate disrupt the glandular structures evocating atrophy and reactive changes. $\mathbf{d}$ (Hematoxylin and Eosin, $\times 10)$ : this is a picture of the same patient after therapy. You can appreciate the lamina propria devoid of inflammatory infiltrate. The glands are well separated, normoconformed and with a goblet component normorapresented. Just in a focal small field there's a linfomonocytic infiltrate, where no one can appreciate eosinophilic component. e (Hematoxylin and Eosin, $\times 20$ ): a particular of the previous, where glands are normal and neither a significant eosinophilic infiltrate, nor reactive hyperchromatic changes, nor mucin depletion can be appreciated. $\mathbf{f}$ (Hematoxylin and Eosin, $\times 20$ ): as the previous one, glandular mucosal component is conserved and just a focal eosinophilic infiltrate in three different glands is present, but without any specific feature

eosinophilic conditions other than asthma. Several laboratory and clinical items improved during therapy; moreover MEP showed to be useful as steroid sparing agent. As for AERD, interestingly, at the moment, after 2 years treatment, symptom scores for anosmia (Question 21 from the SNOT-22) and nasal congestion (Question 22 from the SNOT-22) are significantly decreased. Also the response of nasal symptoms and the CT findings obtained with MEP in this patient are remarkable and confirm more recent literature data [9].

\section{Conclusion}

This case suggests that MEP could be effective in the treatment of eosinophilic disorders other than asthma, i.e. EGE and AERD. Obviously long term observations and further investigations are needed to define better the therapeutic management of these diseases, however the description of different cases with different comorbidities could help to define different aspects of therapy in terms of schedule, drug dosage, duration and so on. 


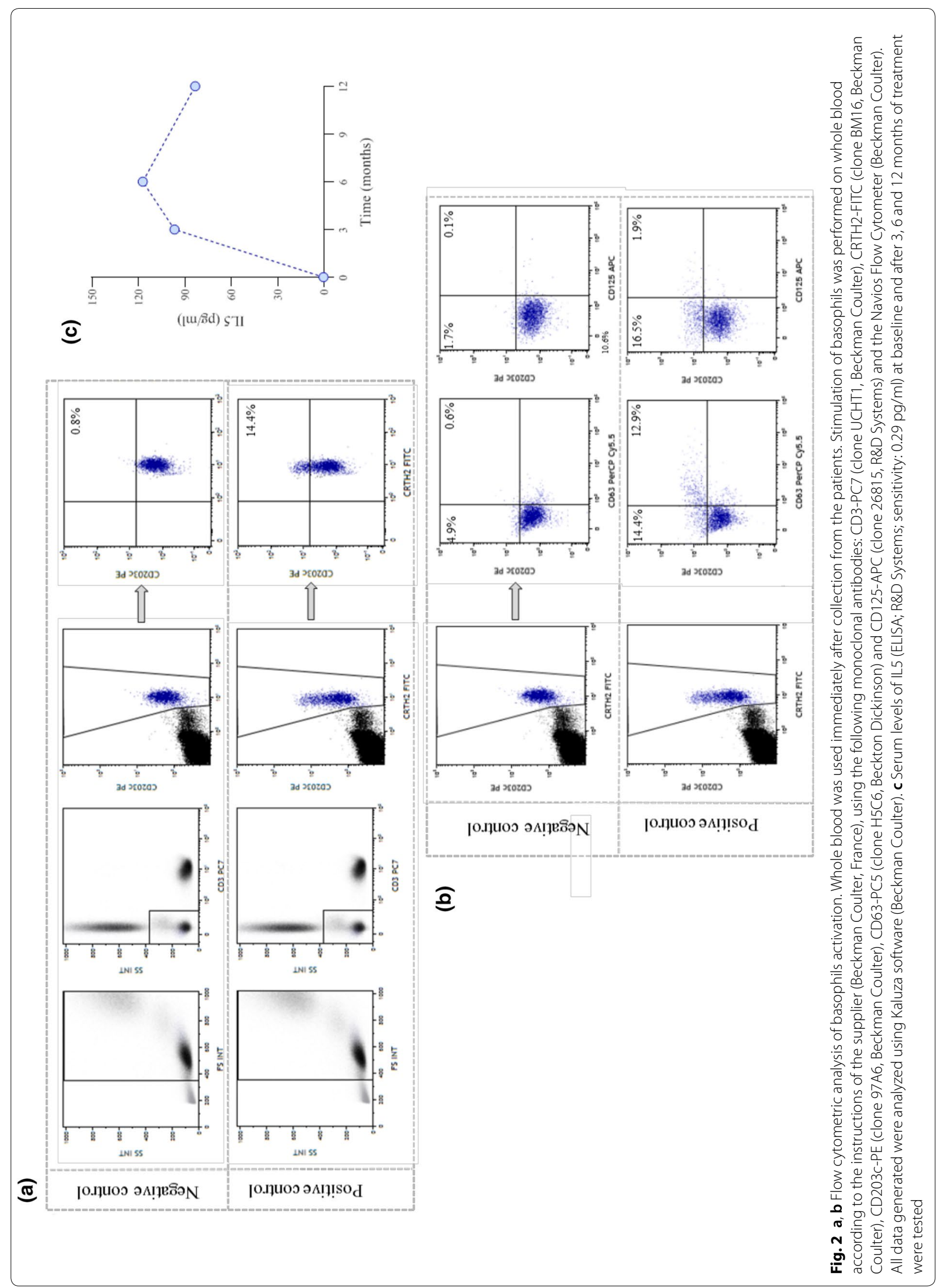




\section{Abbreviations}

MEP: Mepolizumab; AERD: Aspirin-exacerbated respiratory disease; COX: Cyclooxygenase; EGE: Eosinophilic gastroenteritis; EGID: Eosinophilic gastrointestinal disorder.

\section{Acknowledgements}

Not applicable.

\section{Authors' contributions}

CC and SC equally contributed in writing the paper. CDM, BT and EG contributed to laboratory assay, GP performed endoscopic procedures, FC performed and described the histological findings, AG, AR and AA coordinated multidisciplinary work. All authors read and approved the final manuscript.

\section{Funding}

I declare that I didn't received any form of funding for the writing of this clinical case.

\section{Availability of data and materials}

The data used during the current report are available from the corresponding author on reasonable request.

\section{Ethics approval and consent to participate}

Not applicable.

\section{Consent for publication}

l obtained the patient's informed consent for the publication of the images and biopsy data on tissue.

\section{Competing interests}

I declare that I haven't competing interests.

\section{Author details}

${ }^{1}$ Allergy Unit, Fondazione Policlinico Universitario A. Gemelli, IRCCS, Rome, Italy. ${ }^{2}$ Department of Translational and Precision Medicine, Sapienza University, Rome, Italy. ${ }^{3}$ IBD UNIT Presidio Columbus, Fondazione Policlinico Universitario A. Gemelli IRCCS, Rome, Italy. ${ }^{4}$ Division of Rheumatology, Università Cattolica del Sacro Cuore, Rome, Italy. ${ }^{5}$ Division of Rheumatology, Fondazione Policlinico Universitario A. Gemelli IRCCS, Rome, Italy. ${ }^{6}$ Digestive Endoscopy Unit, Fondazione Policlinico Universitario A. Gemelli IRCCS, Rome, Italy. ${ }^{7}$ Polo Scienze della Salute della Donna e del Bambino-Area Anatomia Patologica-Fondazione Policlinico Universitario A. Gemelli IRCCS,
Università Cattolica del Sacro Cuore, Rome, Italy. ${ }^{8}$ Department of Internal Medicine and Gastroenterology, Fondazione Policlinico A. Gemelli IRCCS, Università Cattolica Sacro Cuore, Rome, Italy. ${ }^{9}$ Casa di Cura Quisisana, Rome \& Fondazione Mediterranea G.B. Morgagni, Catania, Italy.

Received: 3 February 2020 Accepted: 3 April 2020

Published online: 22 April 2020

\section{References}

1. Cortellini G, Caruso C, Romano A. Aspirin challenge and desensitization: how, when and why. Curr Opin Allergy Clin Immunol. 2017;17(4):247-54.

2. Pineton de Chambrun $\mathrm{G}$, et al. Diagnosis, natural history and treatment of eosinophilic enteritis: a review. Curr Gastroenterol Rep. 2018;20(8):37.

3. Lombardi $\mathrm{C}$, et al. Analysis of the drop-out rate in patients receiving mepolizumab for severe asthma in real life. Pulm Pharmacol Ther. 2019;54:87-9.

4. Potaczek DP, et al. Epigenetics and allergy: from basic mechanisms to clinical applications. Epigenomics. 2017;9(4):539-71.

5. Han D, Lee JK. Severe asthma with eosinophilic gastroenteritis effectively managed by mepolizumab and omalizumab. Ann Allergy Asthma Immunol. 2018;121(6):742-3.

6. Kurosawa M, et al. Favorable clinical efficacy of mepolizumab on the upper and lower airways in severe eosinophilic asthma: a 48-week pilot study. Eur Ann Allergy Clin Immunol. 2019;51(5):213-21.

7. Suzuki Y, et al. Airway basophils are increased and activated in eosinophilic asthma. Allergy. 2017;72(10):1532-9.

8. Pouliquen IJ, et al. Characterization of the relationship between dose and blood eosinophil response following subcutaneous administration of mepolizumab. Int J Clin Pharmacol Ther. 2015;53(12):1015-27.

9. Hagin D, et al. Mepolizumab for the treatment of aspirin-exacerbated respiratory disease associated with coronary spasm. J Allergy Clin Immunol Pract. 2019;7(3):1076-7.

\section{Publisher's Note}

Springer Nature remains neutral with regard to jurisdictional claims in published maps and institutional affiliations.
Ready to submit your research? Choose BMC and benefit from:

- fast, convenient online submission

- thorough peer review by experienced researchers in your field

- rapid publication on acceptance

- support for research data, including large and complex data types

- gold Open Access which fosters wider collaboration and increased citations

- maximum visibility for your research: over $100 \mathrm{M}$ website views per year

At BMC, research is always in progress.

Learn more biomedcentral.com/submissions 